\title{
Explaining The Participation In A Small Group Brand Community: An Extended TRA
}

Pr. Nabil Mzoughi, University of Sousse, Tunisia

Rym Ben Ahmed, University of Sousse, Tunisia Hela Ayed, University of Sousse, Tunisia

\begin{abstract}
This research aims to extend the TRA (theory of reasoned action) by adding social (perceived cohesion, social identity), psychological (self image congruence) and motivational (perceived enjoyment) factors to explain the participation in a small group brand community based around the Counter Strike game. The conceptual model proposes to test the mediating role of the perceived cohesion in the relationship between the perceived enjoyment and the attitude, the impact of the self image congruence on the social identity and the role of desire as a mediating variable for the effects of the subjective norms, the attitude and the social identity on social intentions. This study is conducted nearby 145 gamers, members of the Counter Strike small group brand community. The findings revealed that the perceived cohesion partially mediates the relationship between the perceived enjoyment and the attitude. It also showed that the self image congruence is an antecedent of the social identity. The desire mediates fully the effect of subjective norms and the social identity on social intentions, and partially the impact of the attitude on social intentions.
\end{abstract}

Keywords: brand community, TRA, perceived cohesion social identity

\section{INTRODUCTION}

$\mathcal{B}$ rand community research has distinguished essentially between the network based brand community and the small group brand community (Bagozzi and Dholakia, 2006; Dholakia, Bagozzi, and Pearo, 2004; Muniz and O'Guinn, 2001). The first approach, introduced by Muniz and O'Guinn (2001), treats the brand community as a social network organized around the brand. Social interactions occur within virtual venues in which consumers share information, experiences and feelings about the brand. Even though brand communities have commercial purposes, they are considered as a credible source in guiding customers to make their choices. They are employed as an effective tool making customers loyal and even "evangelical" (Fournier et al in Algesheimer, Dholakia, and Herrmann, 2005, p19). In this setting, firms organize some events and activities related to the brand in order to reinforce and intensify relationships between community members (Algesheimer, Dholakia, and Herrmann, 2005). The second approach takes into account face to face interactions and geographical considerations (Bagozzi and Dholakia, 2006). The members of a small group brand community are close to each other. Harley-Davidson clusters were taken as a prototypical example of this type of gathering (Shouten and McAlexander, 1995). Their activities turn around social actions like "organizing competitions, raising funds for people, protesting political decisions or even encountering in public spaces", in addition to brand related activities (Bagozzi and Dholakia, 2006). Harley devotees act essentially on the basis of their friendship and passion for the brand inside small groups, regardless of formal hierarchical structure (Bagozzi and Dholakia, 2006).

In this article, clusters of Counter Strike gamers are treated as an example of a small group brand community. Counter Strike 1.6, is a tactical first person shooter video game, produced by Valve and has the largest gathering on the net (www.counter-strike.com). Offline clusters of Counter strike are groups of friends sharing the 
same passion around the game and engaged in joint actions like competitions or social encounters. Their interactions occur essentially within videogame clubs.

Participating in such gatherings can be influenced by social and psychological variables. Recent studies have focused on developing a theory of consumers' participation in brand communities (Bagozzi and Dholakia, 2006a, b; Dholakia et al, 2004). On the basis of behavioral theories such as the theory of reasoned action (TRA), the theory of planned behavior (TPB) or the model of goal directed behavior (GDB), some motivational, social and psychological factors are introduced in order to contribute to predict the consumer behavior regarding the brand community (Bagozzi and Dholakia, 2006a, b; Dholakia et al, 2004). Consistent with this perspective, this research seeks to deepen the understanding of social actions in a small group brand community building upon Bagozzi and Dholakia's model (2006a). Their study provides a useful framework for our research. Beyond the traditional antecedents of the TPB (subjective norms, attitude and perceived behavioral control), they consider the impact of anticipated emotions (positive and negative) and social identity on social intentions. Conforming to the model of goal-directed behavior (Perugini and Bagozzi, 2001), desire was introduced as a key mediator factor between the effects of all these variables and social intentions. Despite the relevance and importance of their research, one principal limit can be addressed to their study. As attested by Dholakia et al (2004) the antecedents of exogenous variables were not integrated in their model. Consequently, this study aims firstly to introduce both of perceived cohesion and perceived enjoyment as attitudinal beliefs within the TRA and self image congruence as an antecedent of social identity. The desire is considered as mediating all the effects of subjective norms, attitude and social identity on intentions. The theory of relational cohesion (Lawler and Thye, 1999), the theory of self image congruence (Sirgy, 1982), the theory of extended self (Belk, 1988), and the social identity theory (Ellemers, Kortekaas, and Ouwerkerk, 1999) are therefore employed for developing our research model. Secondly, this study provides the opportunity to guide brand managers to organize and integrate offline small groups of videogame in the development of a brand community.

After the review of the literature, a quantitative study is performed. The sampling frame and data collection procedures are then presented. Analysis and results are discussed as well as implications and future research directions.

\section{RESEARCH MODEL AND HYPOTHESES}

\section{Perceived Enjoyment and Perceived Cohesion in A Small Group Brand Community: Theory of Relational Cohesion}

Within Counter Strike small group, gamers are willing to organize some encounters and informal competitions for entertainment purposes. Theses activities lead to several states of excitement and enjoyment related to the consumption experience of the game within clusters of friends. Perceived enjoyment is seen as a crucial factor for the success of the experience whereas the essential reason for participation in such gatherings is recreational. Perceived enjoyment within the online game community context is defined as "the extent to which the activity of participating in the online game community is perceived to be pleasure and satisfaction" (Hsu and Lu, 2007). The more gamers enjoy the participation process in small groups based on the preferred game, the more they positively evaluate their actions toward the community. Two studies consider the impact of perceived enjoyment on the attitude toward the participation in virtual community games and conclude that this concept has a positive impact on the attitude (Hsu and Lu, 2007; Wu and Liu, 2007). For our considerations, perceived cohesion is mediating the relationship between the perceived enjoyment and the attitude. The proposed model determines therefore only the indirect effect of perceived enjoyment on the attitude through the perceived cohesion. This is partially supported by the theory of relational cohesion which highlights the role of emotions in the unity of the group. Within social exchange context, recent researches consider the important role of emotions in sustaining relationships in social network structures (Lawler and Thye, 1999). It is advanced that "joint activity reaffirms and strengthens social solidarity because of the shared emotions and feelings it produces" (Durkheim in Lawler and Thye, 1999, p223). Consistent with the proposals of this theory, perceived enjoyment related to the process of participation in small group of Counter Strike strengthens the solidarity between the members' group. Gamers pleased and satisfied of their experiences within the group, build a tightly and closely relationships with members in order to maintain their practice around their favorite game. The success of collective actions and the perceiving of positive outcomes can 
not be achieved when the relationships inside small group are loosely and members are not able to act in the best interest of the group. The perceived cohesion plays therefore a key role in participating in small group of Counter Strike. On the basis of previous researches, perceived cohesion is in turn considered as a determinant of the behavioral attitude (Hsu and Lu, 2007). When the individual perceives that he maintains an intimately relationships with members' group, he develops a favorable or a positive attitude regarding participating in groups' activities and events. On the basis of this discussion, it is possible to hypothesize that:

Hypothesis 1: Perceived cohesion mediates the relationship between the perceived enjoyment and the attitude.

\section{Self Image Congruence and Social Identity in A Small Group Brand Community: Beyond the Theory of the} Extended Self

Consistent with the phenomenological approach, the self is studied in a holistic form (Sirgy, 1982). It goes beyond one's "possessions, perceptions and experiences" that constitute the self and extends to "persons, objects, places and group possessions" which form the extended self (Belk, 1988, p140). Possessions are considered not only as a communicative and constructive device that maintain and enhance the personal identity but also as mediating interpersonal relationships (Ahuvia, 2005; Belk, 1988). "Relationships with objects are never two-way (personthing) but always three-way (person-thing-person)" (Belk, 1988). Brand community is therefore a form of extended self through which consumers build relationships and construct a social identity based on the shared passion, enthusiasm and experiences around a specific brand (Muniz and O'Guinn, 2001). From our perspective, it is important to advance that consumer-brand relationship seems to precede the consumer-consumer relationships. Consumers holding a strong relationship with the brand are able to be connected to other devotees (Algesheimer et al, 2005). When they attempt to construct and define their selves, they strive to possess brands which images are similar to their self perceptions and build relationships that assist their choices and construct a social identity. This is coherent with Algesheimer et al (2005) research in which they consider that brand-consumer relationship is a predictor of community identification. Meanwhile, this hypothesis is contradictory maintained by Bagozzi and Dholakia's study (2006a). They sustain that consumer-brand identification is a consequence of social identity whereas brand-consumer relationship will be strengthened after joining small group brand community. Within this setting, the first relationship is predicted coherently with our previous discussion. Therefore,

Hypothesis 2: Self image congruence has a positive influence on the social identity.

\section{The Mediating Role of Desire: Bagozzi and Dholakia's (2006) Model}

The mediating role of desire in the TPB was essentially introduced by Perugini and Bagozzi (2001) within the model of goal directed behavior (MGB). They sustain that all the processes established in the model work through the desire. It is maintained that the traditional antecedents of the TPB are a "rational reasons for acting". Meanwhile, they lack an "explicit motivational" factor that pushes the intention to act (Bagozzi and Dholakia, 2006; Perugini and Bagozzi, 2001). Desire is therefore considered as a catalyst that "energizes" intentions to achieve actions (Perugini and Bagozzi, 2001). Furthermore two conditions are determined to explain in which way this can be happened. Under "volitive desires", the consumer constructs a self-commitment to act which afterward encourages him to perform the action. "With appetitive desires reasons for acting serve as catalysts to release or free-up a hidden or latent desire related to such biological needs as food, sex, or safety" (Bagozzi and Dholakia, 2006, p70). For our purposes, the "volitive desires" are considered, whereas the desire is introduced as a mental statement that influences social intentions and not as arousing statement that lead consumers to act. Accordingly, the desire can be defined as " $a$ state of mind whereby an agent has a personal motivation to perform an action or to achieve a goal" (Perugini and Bagozzi, 2004, p71). Consistent with this view, desire occurs as a mediator factor in our model. It mediates the impact of subjective norms, the attitude and the social identity on social intentions. This is can be sustained by the research of Bagozzi and Dholakia (2006) in which they attest that desire fully mediates the effects of attitude, emotions, subjective norms, perceived behavioral control and social identity on social intentions. Therefore, it is possible to hypothesize that:

Hypothesis 3: The desire mediates the effect of subjective norms on the social intentions. 
Hypothesis 4: The desire mediates the impact of the attitude on the social intentions.

Hypothesis 5: The desire mediates the influence of the social identity on the social intentions.

Based on the above hypotheses, a conceptual model is developed (Figure 1):

Figure1: Research Model

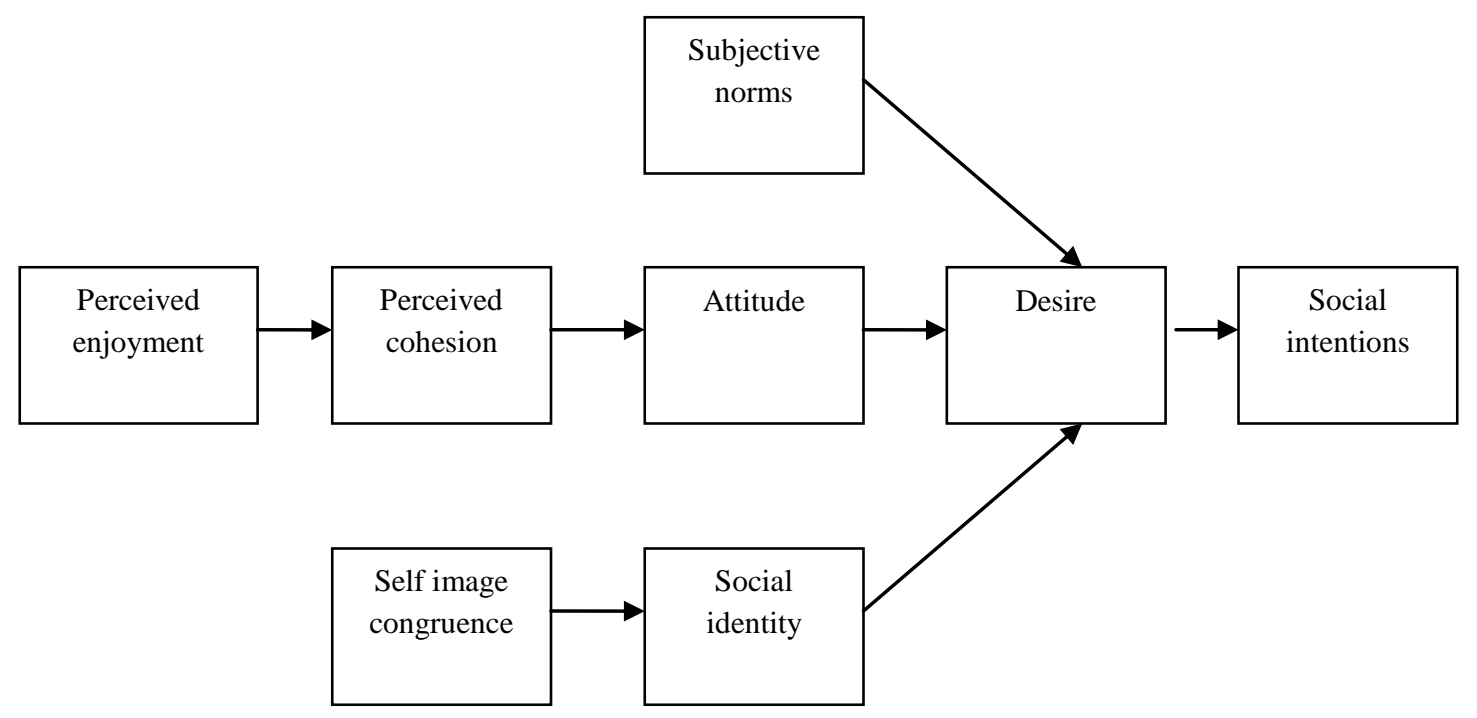

\section{EMPIRICAL STUDY}

\section{Participants and Procedure}

Counter Strike clusters meet in videogame clubs which propose several other games. The choice of the small groups of the Counter Strike community is related to the game notoriety. International competitions are regularly organized. This game generates one of the largest gatherings on the net (www.counter-strike.com) and offline groups which encounter regularly within the framework of non official competitions for leisure purposes.

Clubs' owners encouraged members to participate in the survey which has been performed during a period of two months from $15^{\text {th }}$ of July to $15^{\text {th }}$ of August 2008. 250 questionnaires were distributed in four clubs. 170 members returned the questionnaires and only 145 questionnaires were entirely completed. At the beginning of the questionnaire, it was noticed that only members that engage in regularly activities within small groups of Counter Strike devotees that were targeted by the survey.

All variables were measured by multi items scales stemmed from previous researches (Appendix 1). To make sure that items are well structured, a pre-test was conducted nearby fifteen gamers.

The sample encompasses small groups varying from 6 to 10 members. Surprisingly, only men participated to our survey. This may be due to the nature of the game: war strategy. $22.8 \%$ are 13 to 16 years old. $62 \%$ are aged from 17 to 25 years, and only $14.5 \%$ from 26 to 30 years. A unique individual has more than 30 years. 


\section{Data Analysis and Results}

Initially, all measures were tested for their internal consistency using Cronbach's Alpha. Factor structures were determined via principal components analyses. Secondly, separate regression analyses were conducted for all relationships proposed by the conceptual model. Finally, mediating tests were assessed coherently with the procedure recommended by Baron and Kenny (1986). SPSS .15 was employed for theses purposes.

\section{Psychometric Quality of the Scales}

All measures reveal a high reliability ( $\alpha \geq 0.7$ ) as requested by Nunnaly (1978). As in the literature, all the scales are one-dimensional, except social identity. In contrast with Bagozzi and Dholakia (2006), social identity is a one-dimensional construct.

\section{Mediating Role of the Perceived Cohesion in the Relationship between the Perceived Enjoyment and the Attitude}

The separate direct effects of perceived enjoyment and perceived cohesion on attitude and perceived enjoyment on perceived cohesion were sustained. Both of the perceived enjoyment $(\beta s=.896, p<0.05)$ and the perceived cohesion $(\beta \mathrm{s}=.923, \mathrm{p}<0.05)$ significantly and positively affect the attitude toward participating in small group brand community. The impact of perceived enjoyment on perceived cohesion is significant and positive $(\beta \mathrm{s}=.888, \mathrm{p}<0.05)$.

In order to test $\mathrm{H1}$, a multiple regression was conducted. Results indicate that the regression model is globally significant $(\mathrm{F}=516.318, \mathrm{p}<0.05)$. The effect of perceived enjoyment on attitude toward participating in small brand community through perceived cohesion was attenuated $(\beta s=.359, p<0.05)$ comparing to the direct effect established previously. $\mathrm{H} 1$ is therefore partially sustained whereas the impact of perceived cohesion on the attitude is significant, positive and more important $(\beta \mathrm{s}=.604>.359, \mathrm{p}<0.05)$ than the effect of perceived cohesion on the attitude which is always significant.

\section{Impact of the Self-Image Congruence on the Social Identity}

On the basis of simple regression findings, self image congruence significantly and positively influence social identity $(\beta \mathrm{s}=.625, \mathrm{p}<0.05)$. $\mathrm{H} 2$ is consequently retained.

\section{Mediating Role of the Desire in the Separate Effects of Subjective Norms, Attitude and Social Identity on Social Intentions}

\section{Mediating Role of the Desire in the Relationship between Subjective Norms and Social Intentions}

Both of subjective norms $(\beta \mathrm{s}=.857, \mathrm{p}<0.05)$ and desire $(\beta \mathrm{s}=.904, \mathrm{p}<0.05)$ significantly and positively affect social intentions. Subjective norms have a significant and positive impact on desire $(\beta s=.904, p<0.05)$.

On the basis of simple regression analyses, the separate direct effects of subjective norms and desire on social intentions and subjective norms on desire are supported as previously revealed. Besides, in order to achieve the mediating tests, the effect of subjective norms and desire on social intentions should be performed. Multiple regression analyses were consequently employed. Results indicate that the regression model predicting social intentions is overall significant $(\mathrm{F}=337.385, \mathrm{p}<0.05)$. The impact of subjective norms on social intentions is nevertheless non significant $(\beta \mathrm{s}=.218, \mathrm{p}>0.05)$. Indeed, desire fully mediates $(\beta \mathrm{s}=.707, \mathrm{p}<0.05)$ subjective norms and social intentions relationship. $\mathrm{H} 3$ is therefore sustained.

\section{Mediating Role of the Desire in the Relationship between the Attitude and Social Intentions}

The separate impacts of attitude $(\beta \mathrm{s}=.884, \mathrm{p}<0.05)$ and desire $(\beta \mathrm{s}=.904, \mathrm{p}<0.05)$ on social intentions are positive and significant. Simple regression analyses indicate that attitude has a significant and positive $(\beta \mathrm{s}=.936$, $\mathrm{p}<0.05$ ) impact on desire. 
Multiple regression analyses were conducted to test the mediating effect of the desire in attitude social intentions relationship. The regression model is fully significant $(F=345.188, p<0.05)$. Despite of the significance and positive $(\beta \mathrm{s}=.309, \mathrm{p}<0.05)$ relationship between the attitude and social intentions, the later is attenuated under desire effect $(\beta s=.615, \mathrm{p}<0.05)$. H4 is therefore partly supported.

\section{Mediating Role of the Desire in the Relationship between the Social Identity and Social Intentions}

Both social identity $(\beta \mathrm{s}=.856, \mathrm{p}<0.05)$ and desire $(\beta \mathrm{s}=.904, \mathrm{p}<0.05)$ have a separate significant and positive influence on social intentions. desire.

Simple regression analyses specify that social identity significantly and positively $(\beta s=.907, p<0.05)$ impact

In order to test H8, multiple regression analyses were performed. Results attest that the regression model predicting the relationship between social identity, desire and social intentions is on the whole significant $(\mathrm{F}=334.039, \mathrm{p}<0.05)$. Social identity has non significance $(\beta \mathrm{s}=.202, \mathrm{p}>0.05)$ impact on social intentions. Consequently, desire mediates $(\beta \mathrm{s}=.721,<0.05)$ the effect of social identity on social intentions. H5 is therefore supported.

\section{DISCUSSION, IMPLICATIONS AND FUTURE RESEARCH}

This research was conducted to highlight some relevant variables that explain consumer participation in small group brand community. The findings attest that participation in a small group brand community is influenced by motivational, social and psychological factors that lead consumers to organize some joint actions. The effect of the perceived enjoyment on the perceived cohesion was successfully supported. This is consistent with the relational exchange literature which considers that emotions strengthen and intensify relationships in social network structure (Lawler and Thye, 1999). The mediating role of the perceived cohesion in the relationship between the perceived enjoyment and the attitude was also retained in this study. This result is noteworthy, providing the evidence that within small group brand community, essentially based offline, the strength of social relationships is determinant of the ongoing contacts and thus the survive of the group around the brand. Despite of the importance of the enjoyment in recreational activities (Vorderer et al, 2004), within Counter Strike small group the unity and solidarity of the group seems to be a central factor in the success of the experience. Such results offer the possibility to arrange and organize these groups within specialized clubs in order to provide an appropriate social environment for the development of such gatherings.

Self image congruence was found a good predictor of social identity. From a theoretical stand point, this result highlights the social nature of the brand in supporting the individual to construct his personal and social identity through his social affiliation, belongingness and participation in brand community (Ahuvia, 2005; Algesheimer et al, 2005; Shouten and McAlexander, 1995; Belk, 1988). The brand is therefore mediating social relationships building upon brand identification (Ahuvia, 2005). Consistently with Algesheimer et al (2005), this relationship provides a mean to develop the symbolic characteristics of the brand in order to attract the most identified one to integrate the brand community. This relationship was also be studied by Bagozzi and Dholakia (2006a) from a different perspective. They sustained that brand identification is deepened through social identification with the brand community. This is can be worthy in the way that emphasizes the role of brand community in creating a more involved and experienced consumers.

Our findings regarding the mediating role of desire showed that the latter fully mediates the effects of subjective norms and social identity on intentions (Bagozzi and Dholakia, 2006a) but surprisingly partially mediates the effect of attitude on intentions. This result is non consistent with Bagozzi and Dholakia (2006) research in which they found that desire fully mediates the impact of the attitude on intentions for both Harley riders and non Harley riders group. This is can be due to the similarity between the attitude measure, in which the respondents were asked if they like, is it funny or attractive to participate in some activities within the group, and desire measure, in which respondents were asked to express their desire to participate in some activities or competitions within the group. 
From a practical standpoint, our findings provide new insights into research about consumer participation in brand communities. Firstly, video game brand managers must create a specialized clubs based around their brand in order to encourage encounters regularity and assure enjoyable experiences. Such actions involve the unity and the solidarity of the group gamers in the fulfillment of their purposes. Secondly, designers should develop a distinctive game personality that serves to construct the gamers' selves and facilitates connection and relationships between admirers of the game. Finally, it will be beneficial to target the most experienced and identified one to the community to develop the hardcore and insure feed-back and cooperation with the firm.

Nevertheless, a number of limitations can be addressed. Data were collected using non-probabilistic convenience sampling procedure. The ability to generalize the findings to the entire population is reduced. The sample is small which impedes us to use Structural Equation Models (SEM) in order to validate our research model. Future researches can therefore validate this model. It is also important to incorporate further pertinent variables (gamers' expertise, game involvement, functional congruity) in order to deepen the explaining of the participation in a brand community.

\section{AUTHOR INFORMATION}

Nabil Mzoughi is professor of marketing at ISG Sousse, Tunisia. He is former dean of a higher institute of technological studies. He teaches undergraduate and graduate courses in advertising, negotiation, e-marketing, marketing theory and marketing strategy. Pr. Mzoughi is the director of the research unit $\mathrm{MaPreCoB}$ at the University of Sousse and supervises several Ph.D. researches. His works are published by various international journals. He also intervened as a senior consultant in many industrial firms in Tunisia.

Rym Ben Ahmed is a Ph.D. student in marketing at the University of Tunis, Tunisia. She is interested in studying online consumer behavior and brand community.

Hela Ayed is assistant professor of Marketing at the Higher Institute of Trade and Accounting of Bizerte, University of 7 November-Carthage, Tunisia. Dr. Ayed's researches deal with advertising, brand personality and channel design.

\section{REFERENCES}

1. Ahuvia, A.C., (2005). Beyond the extended self: loved objects and consumers' identity narratives. Journal of Consumer Research, Vol. 32 No. 1, pp. 171-184.

2. Algesheimer R., Dholakia U.M, and Hermann A. (2005). The social influence of brand community: Evidence from European car clubs, Journal of Marketing, Vol. 69 No. 3, pp. 19-34.

3. Atman, B., and Ülengin B. (2003). A note on the effect of brand image on sales. Journal of Product and Brand Management, Vol. 12 No. 4, pp. 237-250.

4. Bagozzi R.P, and Dholakia, U.M (2006a). Antecedents and purchase consequences of customer participation in small group brand communities, International Journal of Research in Marketing Vol. 23, pp. 45-61.

5. Bagozzi, R.P., and Dholakia, U.M. (2006b). Open source Software user communities: A study of participation in Linux user groups Richard. Management Science, Vol. 52 No. 7, pp. 1099-1115.

6. Baron, R. M., and Kenny, D. A. (1986). The moderator-mediator variable distinction in social psychological research: Conceptual, strategic, and statistical considerations. Journal of Personality and Social Psychology, Vol. 51 No. 6, pp. 1173-1182.

7. Belk, R.W. (1988). Possessions and the Extended Self, Journal of Consumer Research, Vol. 15 No. 2.

8. Dholakia, U. M., Bagozzi, R. P., and Pearo, L. R. K. (2004). A social influence model of consumer participation in network- and small-group-based virtual communities. International Journal of Research in Marketing, Vol. 21 No. 3, pp. 241-263.

9. Dolich, I.J. (1969). Congruence relationships between self images and product brands. Journal of Marketing Research, Vol. 6 No. 1, pp. 80-84. 
10. Ellemers, N., Kortekaas, P., and Ouwerkerk, J. W. (1999). Self-categorization, commitment to the group and group self-esteem as related but distinct aspects of social identity. European Journal of Social Psychology, Vol. 29 No. (2-3), pp. 371-389.

11. Graeff, T.R. (1997). Consumption situations and the effects of brand image on consumers' brand evaluations. Psychology and Marketing, Vol. 14 No. 1, pp. 49-70.

12. Grewal, R., Mehta, R. and Kardes, F.R. (2000). The role of the social-identity function of attitudes in consumer innovativeness and opinion leadership. Journal of Economic Psychology, Vol. 21, pp. $233-252$.

13. Herrmann, A., Heintmann, M., Sirgy, M.J, and Hohenstein, N (2007). Self-congruity: Antecedents and consequences. Proceedings of LaLonde-Les Maures Conference on Consumer Behavior.

14. Hong, J.W., and Zinkhan, G.M. (1995). Self-concept and advertising effectiveness: The influence of congruency, conspicuousness and response mode. Psychology and Marketing, Vol. 12 No. 1, pp. 53-77.

15. Hsu, C.L and Lu, H.P. (2007). Consumer behavior in online game communities: A motivational factor perspective. Computers in Human Behavior, Vol. 23, pp. 1642-1659.

16. Kassarjian, H.H. (1971). Personality and consumer behavior: A review, Journal of Marketing Research, Vol. 8 No. 4, pp. 409-418.

17. Lawler, E.J., and Thye. S.R. (1999). Bringing Emotions into Social Exchange Theory. Annual Review of Sociology, Vol. 25, pp. 217-44.

18. Lawler.E.J; Thye. S.R. and Yoon.J. (2000). Emotion and group cohesion in productive Exchange. The American Journal of Sociology, Vol. 106 No. 3, pp. 616-657.

19. Lawler.E.J; Thye. S.R. and Yoon.J. (2006). Commitment in structurally enabled and induced exchange relations. Social Psychology Quarterly, Vol. 69 No. 2, pp.183-200.

20. McCarthy, P.J., Jones, M.V. and Clark-Carter, D. (2008). Understanding enjoyment in youth sport: A developmental perspective. Psychology of Sport and Exercise, Vol. 9, pp. 142-156.

21. Muniz A.Jr and O’Guinn T. (2001). Brand Community, Journal of Consumer Research, Vol. 27, pp. 412432.

22. Nunnally, J. C. (1978). Psychometric theory, 2nd ed. New York, NY: McGraw-Hill.

23. Schouten, J.W., and McAlexander, J. H. (1995). Subcultures of consumption: An ethnography of the new bikers. Journal of Consumer Research, Vol. 22 No. 1, pp. 43-61.

24. Sirgy, M.J. (1982). Self-Concept in Consumer Behavior: A Critical Review. Journal of Consumer Research, (pre-1986), Vol. 9 No. 3, pp. 287-301.

25. Tidwell, M.V. (2005). A social identity model of prosocial behaviors within nonprofit organization, Nonprofit Management and Leadership, Vol. 15 No.4, pp. 449-467.

26. Vorderer, P., Klimmt, C., and Ritterfeld, U. (2004). Enjoyment: At the heart of media entertainment. Communication Theory, Vol. 14 No 4, pp. 388-408.

27. Wu, J and Liu, D. (2007). The Effects of Trust and Enjoyment on Intention to Play Online Games. Journal of Electronic Commerce Research, Vol. 8 No. 2, pp. 128-140. 


\section{APPENDIX 1 Constructs and Measures}

\author{
Perceived cohesion (Hunton and al, 2001) \\ I fit in well with my group of Counter Strike \\ I am comfortable as a member of my group of Counter \\ Strike \\ I like the members of my group of Counter Strike \\ My group of Counter Strike acts as a cohesive unit \\ I trust the members of my group of Counter Strike to act \\ in the best interest of the group (7-point scale) \\ Perceived enjoyment (Hsu and Lu, 2007) \\ The process of participating to the group of Counter \\ Strike is enjoyable \\ While participating in the group of Counter Strike, I \\ experienced pleasure \\ Overall, I believe that the group of Counter Strike is \\ playful (5-point scale)
}

Attitude (Wu and Liu, 2007)

It is a lot of fun to participate in activities with the group of Counter Strike

I like to participate in activities with the group of

Counter Strike

Participating in activities with the group of Counter

Strike is attractive (7-point scale)

Subjective norms (Bagozzi and Dholakia, 2006)

Please express how strongly most people who are

important to me feel

I should participate in activities such as competitions, tournaments, and encounters with my group of Counter Strike (7-point scale)

Would approve to me participating in activities such as competitions, tournaments, and encounters with my group of Counter Strike (7-point scale)

Self image congruence (Hohenstein and al, 2007)

I can completely identify with Counter Strike

Counter Strike is a lot like me

Counter Strike reflects what I am

Counter Strike is exactly how I see myself

If I was a game, I would be Counter Strike

Counter Strike image corresponds to my self-image in

many respects

Through Counter Strike I can express what I find

important in life. (9-point "strongly disagree" (1) to

"strongly agree" (9) scale)
Desires (Bagozzi and Dholakia, 2006)

I desire to participate in activities such as competitions, tournaments, and encounters with my group of Counter Strike (7-point "agree-disagree" scale)

My desire for participating in activities such as competitions, tournamnts, and encounters with my group of Counter Strike can be described as (7-point "very weak desire-very strong desire" scale) I want to participate in activities such as competitions, tournaments, and encounters with my group of Counter Strike (7-point "does not describe me at alldescribes me very much" scale)

Social intentions (Bagozzi and Dholakia, 2006)

I intend that our group participate in activities such as competitions, tournaments, and encounters during the next one month (5-point "strongly agree-strongly disagree" scale) We intend to participate in activities such as competitions, tournaments, and encounters sometime during the next one month (5-point "strongly agreestrongly disagree" scale)

Social identity (Bagozzi and Dholakia, 2006) Cognitive social identity

How would you express the degree of overlap between your personal identity and the identity of the group of Counter Strike you mentioned above? (8point graphical "not at all-very much" scale) Please indicate to what degree your self-image overlaps with the identity of the group of Counter Strike? (7-point "not at all-very much" scale)

\section{Affective social identity}

How attached are you to the group of Counter Strike you mentioned above? (7-point "not at all attachedattached very much" scale)

How strong would you say your feelings of belongingness are toward the group you indicated above? (7-point "not at all strong-very strong" scale) Evaluative social identity

I am a valuable member of the group I indicated above" (7-point "does not describe me at alldescribes me very well" scale)

I am an important member of the group I indicated above" (7-point scale; same as first measure) 


\section{NOTES}

